\title{
The effect of karate training on changes in physical fitness in school-age children with normal and abnormal body weight
}

\author{
DOI: https://doi.org/10.5114/pq.2019.86465
}

\author{
Tomasz Rutkowski', Krzysztof Andrzej Sobiech², Agnieszka Chwałczyńska ${ }^{2}$ \\ 1 Jan Dlugosz University in Czestochowa, Czestochowa, Poland \\ ${ }^{2}$ Department of Cosmetology, Human Biology Unit, University School of Physical Education in Wroclaw, Wroclaw, Poland
}

\begin{abstract}
Introduction. Physical activity is one of the best methods to prevent civilization diseases in modern times. Studies confirm that the appropriate dose reduces the risk of hypertension, heart diseases, cancer, depression, or overweight and obesity. Methods. The aim of the study was to assess the changes in individual physical fitness tests among children in early school age participating in karate training. A total of 59 children attending primary school were examined. Selected Eurofit tests were carried out before and after 10 weeks of karate training.

Results and conclusions. Karate training induced positive changes in the fitness of the studied children. Higher improvements were observed among children with normal body mass as compared with the overweight or obese ones.

Key words: children body weight, karate training for children, body weight abnormalities in children, school-age children, physioprevention
\end{abstract}

\section{Introduction}

Maintaining one's physical fitness is among the best methods for preventing illnesses associated with today's sedentary lifestyle. Being fit enables an individual to be physically active, and when optimized, activity can improve certain parameters of physical and mental health [1-3]. The relationship between an individual's level of fitness and physical performance and health is significant enough for some researchers to claim that they may be an effective health marker. The functional skills of all bodily systems are tested in order to determine their levels [4]. Research confirms that the proper amount of physical activity lowers the development of health risks associated with high blood pressure, heart conditions, tumours, depression, excess body weight, and obesity. The World Health Organization (WHO) guidelines recommend 30 minutes of moderate activity daily, 5 days per week. For children and adolescents, according to WHO, the recommended amount of physical activity needed to improve proper physical and mental development is higher: up to $60 \mathrm{~min}-$ utes per day [5]. In order to comply with the directives given by the Ministry of National Education, young children have 3 lesson hours (45 minutes each) of physical education scheduled each week. This amounts to $28 \%$ of the WHO recommendations [6]. According to research conducted by Ćwirlej et al. [7] in a group of 10-year-olds, merely $33.7 \%$ of the subjects fulfilled the set norms. Average physical activity (estimated to be $4-5$ hours per week) is performed by $39.6 \%$, whereas on the low and extremely low ends (less than 3 hours), the figure is $26.8 \%$.

Nowadays, there is a lack of physical fitness in children and a significant increase in those who are considered overweight or obese can be observed. In recent years, the percentage of children diagnosed with obesity $(2-3 \%)$ has in- creased [8]. Research that was conducted in a sample of children and adolescents in Wrocław, Poland, indicates that among 8-year-olds, being overweight or obese is an issue for $22 \%$ of boys and $21 \%$ of girls, whereas in an older group, the disorder affected $15 \%$ of boys and $12 \%$ of girls $[9,10]$.

A crucial time regarding childhood motor development is early childhood. This is also when an increased amount of time is spent in the sitting position during school activities. Moreover, in this period, a child learns new motor skills most rapidly [11]. In order to influence all the given factors, physical activity developing all the motor skills along with physical performance should be chosen for a child. One such activity is karate, a martial art which originated in Japan. In karate, self-development is equally important as self-defence [12]. Martial arts training can lead to improvements in strength, balance, flexibility, and agility. Individuals who participated in such training experienced an increased sense of well-being and self-confidence, and a willingness to compete [13].

The aim of this paper was to measure and evaluate how karate training affected the physical fitness of children.

\section{Subjects and methods}

\section{Participants}

A group of 59 children in grades 1-3 of a primary school in Lewin Brzeski, Poland, took part in a study focused on the prevention of abnormal weight gain in children. The average age of the subjects was $7.6 \pm 0.4$ years, the average height: $128.7 \pm 5.8 \mathrm{~cm}$, the average weight: $29.6 \pm 6.9 \mathrm{~kg}$, the average body mass index (BMl): $17.7 \pm 3.1 \mathrm{~kg} / \mathrm{m}^{2}$, whereas the BMI percentile regarding age and sex amounted to $62.7 \pm 30.1$. There were 29 girls and 30 boys in the study.

Correspondence address: Tomasz Rutkowski, Institute of Physical Education, Tourism, and Physiotherapy, Jan Dlugosz University in Czestochowa, al. Armii Krajowej 13/15, 42-218 Częstochowa, Poland, e-mail: t.rutkowski@ajd.czest.pl 
All children whose physical activity was less than 5 hours per week were invited to the program (the data were obtained with the help of the International Physical Activity Questionnaire). Children who participated in karate training were divided into 4 groups depending on their sex and body weight. One group was made up of boys of normal weight $(B / N)$, one group of boys considered overweight or obese $(B / O)$, and similar groups were created for girls $(\mathrm{G} / \mathrm{N}, \mathrm{G} / \mathrm{O})$ :

- the $\mathrm{G} / \mathrm{N}$ group $(n=15)$ were girls whose BMl was stated to be below the $85^{\text {th }}$ percentile according to age, with body fat percentage (FatP) $<25 \%$, based on physical examinations;

- the G/O group ( $n=14$ ) were girls whose BMl was stated to be above the $85^{\text {th }}$ percentile according to age, with/or FatP > 25\%, based on physical examinations;

- the B/N group $(n=15)$ were boys whose BMl was stated to be below the $85^{\text {th }}$ percentile according to age, with FatP $<20 \%$, based on physical examinations;

- the B/O group $(n=15)$ were boys whose BMl was stated to be above the $85^{\text {th }}$ percentile according to age, with/or FatP $>20 \%$, based on physical examinations.

The group profile is presented in Table 1.

Both girls and boys in the overweight groups had statistically significantly higher body weight, BMI, BMI percentile, and FatP compared with children with normal body weight. A statistically significant difference was also observed between girls and boys with normal body weight with regard to FatP and age. The results are presented in Table 2.

\section{Procedure}

\section{Stage I}

In the first stage, body mass and composition were measured by using a BC-418MA body composition analyser, produced by Tanita, and height was determined with a Seca 217 stadiometer. On the basis of the results, the BMI and BMI percentile were calculated with a BMI calculator designed under the Polish nationwide research project OLAF 2007 $2010[14,15]$. The researched children had not participated in any other extracurricular physical activities, nor did they have a leave from physical education lessons. The students participated in physical education lessons conducted by a primary school teacher 3 times per week [6].

In order to determine the subjects' fitness, 6 out of 10 Eurofit fitness tests were conducted. The choice of tests was dependent on the type of exercise performed under health training. The tests measured balance, speed of arm movements, flexibility, dynamic strength (jumping), torso muscular strength, and functional strength (suspension). The obtained results were compared with percentile charts for age and sex.

\section{Stage /I}

After the measurements, the children participated in 10 weeks of karate training based on the International Federation of Karate (IFK) Karate Kyokushin syllabus. The $10 \mathrm{Kyu}$ techniques, a set of techniques for punches, kicks, and blocks, were executed in various stances, such as Sanchin Dachi and Zenkutsu Dachi. The knowledge of these is required to pass the first level of the examination. Characteristic karate training techniques were complemented by elements of running intervals, endurance, and strength training, adjusted to the children's age. Examples of the exercises include walking on 4 legs, hare jumping, and spider walking. Among strength training exercises, there were push-ups, sit-ups, squats, and exercises performed to strengthen back muscles and to activate deep muscles. The exercises were adjusted to the abilities and strength of the subjects. The activities took place in groups of 30 people twice per week, 60 minutes per session. The training was conducted by a karate instructor with a 1 dan degree. After the therapeutic program based on karate training for children, fitness tests were conducted again.

Table 1. Anthropological characteristics of the examined children with the consideration of body mass abnormalities

\begin{tabular}{|l|c|c|c|c|}
\hline Characteristics & $\begin{array}{c}\mathrm{G} / \mathrm{N}, n=15 \\
(\text { average } \pm S D)\end{array}$ & $\begin{array}{c}\mathrm{G} / \mathrm{O}, n=14 \\
\text { (average } \pm S D)\end{array}$ & $\begin{array}{c}\mathrm{B} / \mathrm{N}, n=15 \\
\text { (average } \pm S D)\end{array}$ & $\begin{array}{c}\mathrm{B} / \mathrm{O}, n=15 \\
\text { (average } \pm S D)\end{array}$ \\
\hline Body height $(\mathrm{cm})$ & $126.6 \pm 4.7$ & $129.4 \pm 5.8$ & $127.4 \pm 6.3$ & $131.7 \pm 5.3$ \\
\hline Body mass $(\mathrm{kg})$ & $25.1 \pm 2.7$ & $33.0 \pm 4.2$ & $25.6 \pm 4.5$ & $35.0 \pm 8.6$ \\
\hline BMI $\left(\mathrm{kg} / \mathrm{m}^{2}\right)$ & $15.6 \pm 1.1$ & $19.7 \pm 2.0$ & $15.7 \pm 1.6$ & $20.0 \pm 3.9$ \\
\hline BMI percentile & $45.5 \pm 21.1$ & $87.6 \pm 12.8$ & $39.6 \pm 27.7$ & $80.0 \pm 23.6$ \\
\hline FatP $(\%)$ & $21.6 \pm 2.3$ & $27.4 \pm 3.9$ & $17.4 \pm 2.3$ & $26.0 \pm 5.1$ \\
\hline
\end{tabular}

$\mathrm{G} / \mathrm{N}$ - girls of normal weight, $\mathrm{G} / \mathrm{O}$ - girls considered overweight or obese, $\mathrm{B} / \mathrm{N}$ - boys of normal weight,

$\mathrm{B} / \mathrm{O}$ - boys considered overweight or obese, $S D$ - standard deviation, $\mathrm{BMI}$ - body mass index, FatP - body fat percentage

Table 2. Comparisons for group uniformity

\begin{tabular}{|l|c|c|c|c|}
\hline Characteristics & G/N vs. G/O & B/N vs. B/O & G/N vs. B/N & G/O vs. B/O \\
\hline Body height $(\mathrm{cm})$ & NS & NS & NS & NS \\
\hline Body mass $(\mathrm{kg})$ & 0.000 & 0.001 & NS & NS \\
\hline BMl $\left(\mathrm{kg} / \mathrm{m}^{2}\right)$ & 0.000 & 0.000 & NS & NS \\
\hline BMl percentile & 0.000 & 0.000 & 0.000 & NS \\
\hline FatP $(\%)$ & 0.000 & 0.000 & NS \\
\hline
\end{tabular}

$\mathrm{G} / \mathrm{N}$ - girls of normal weight, $\mathrm{G} / \mathrm{O}$ - girls considered overweight or obese, $\mathrm{B} / \mathrm{N}$ - boys of normal weight,

$\mathrm{B} / \mathrm{O}$ - boys considered overweight or obese, BMI - body mass index, FatP - body fat percentage, NS - not significant 


\section{Statistical analysis}

The Statistica 12 software was used to perform the statistical analysis. In order to characterize the groups, descriptive statistics were used: sample size, sample average, median, minimum and maximum values, and standard deviation. The parametric $t$-Student test was applied for population comparisons. Normality of distribution was assessed with the Shapiro-Wilk test.

\section{Ethical approval}

The research related to human use has complied with all the relevant national regulations and institutional policies, has followed the tenets of the Declaration of Helsinki, and has been approved by the authors' institutional review board or an equivalent committee.

\section{Informed consent}

Informed consent has been obtained from the legal guardians of all individuals included in this study.

\section{Results}

Before the start of the training, Eurofit fitness tests measured fitness, which was compared with the referential value of 50 points per test [16]. In the researched group, boys with normal body weight had statistically significantly higher results in balance and arm movement speed tests, and statistically significantly lower results in the flexibility test compared with the average results. At the same time, 3 tests in which the results were higher than normal were observed in the group. On average, overweight boys achieved lower test results compared with the referential values; however, those differences are not statistically significant. In the overweight girls group, all the test results, except the balance test, differed significantly from the referential values. In the group of girls with normal body weight, statistically significant differences were observed in the flexibility, dynamic strength, and functional strength tests. The average values of the respective performance tests are compared with the referential values in Figure 1.

Statistically significant differences of average values of the arm movement speed test before the health training were observed between girls with normal body weight and excess body weight, overweight girls and boys with normal body weight, boys with normal body weight and boys with excess body weight. Statistically significant differences were reported between overweight girls and boys with normal body weight in the case of functional strength and between overweight girls and overweight boys in the case of abdominal muscles strength.

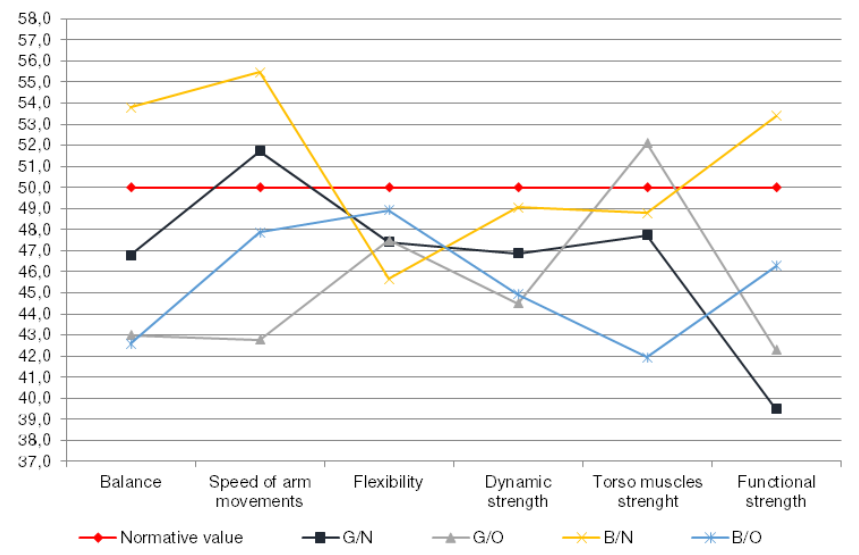

$\mathrm{G} / \mathrm{N}$ - girls of normal weight, $\mathrm{G} / \mathrm{O}$ - girls considered overweight or obese, $\mathrm{B} / \mathrm{N}$ - boys of normal weight, $\mathrm{B} / \mathrm{O}$ - boys considered overweight or obese

Figure 1. Average results of Eurofit fitness tests before karate training

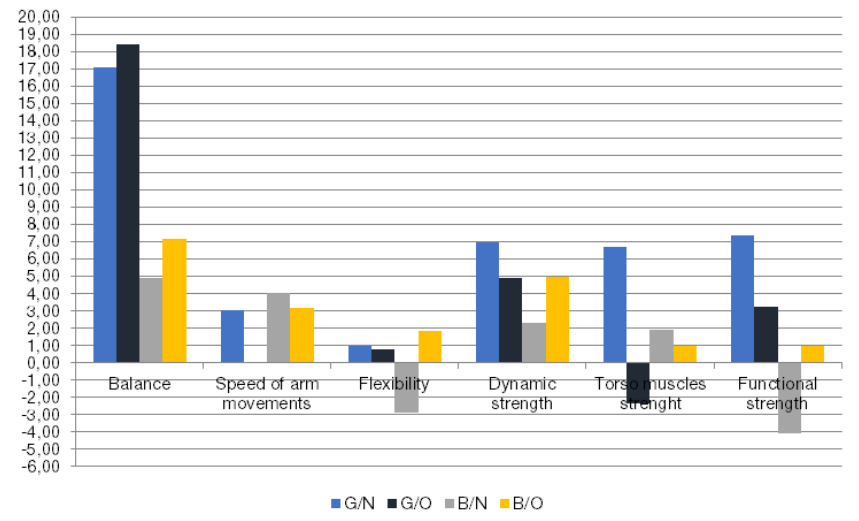

G/N - girls of normal weight, G/O - girls considered overweight or obese, $\mathrm{B} / \mathrm{N}$ - boys of normal weight, $\mathrm{B} / \mathrm{O}$ - boys considered overweight or obese

Figure 2. Changes in fitness among children who participated in karate training

After the implementation of the therapeutic program based on karate training for children, improved fitness was observed in all tests and groups, except for flexibility and functional strength in the group of boys with normal body weight, and abdominal muscular strength in the group of overweight girls. The most statistically significant changes were noted in the group of girls with normal body weight. Furthermore, all the changes indicated an improvement in performance in the respective Eurofit tests. In the case of overweight subjects, regardless of their sex, statistically significant changes were reported only with regard to the dy-

Table 3. Statistical significance of fitness changes in children participating in karate training

\begin{tabular}{|c|c|c|c|c|}
\hline Tested parameter & $\mathrm{G} / \mathrm{N}$ & $\mathrm{G} / \mathrm{O}$ & $\mathrm{B} / \mathrm{N}$ & $\mathrm{B} / \mathrm{O}$ \\
\hline Balance & 0.015 & NS & 0.028 & NS \\
\hline Speed of arm movements & NS & NS & 0.003 & NS \\
\hline Flexibility & NS & NS & NS & NS \\
\hline Dynamic strength & 0.005 & 0.004 & NS & 0.008 \\
\hline Torso muscles strength & 0.007 & NS & NS & NS \\
\hline Functional strength & NS & NS & NS & NS \\
\hline
\end{tabular}

$\mathrm{G} / \mathrm{N}$ - girls of normal weight, $\mathrm{G} / \mathrm{O}$ - girls considered overweight or obese, B/N - boys of normal weight,

$\mathrm{B} / \mathrm{O}$ - boys considered overweight or obese, NS - not significant 
Table 4. Correlation of anthropometric characteristics and fitness changes

\begin{tabular}{|c|c|c|c|c|}
\hline Group & Characteristics & Balance & Speed of arm movements & Dynamic strength \\
\hline \multirow{4}{*}{$\mathrm{G} / \mathrm{N}$} & Age (years) & -0.206 & -0.115 & 0.003 \\
\hline & Body height $(\mathrm{cm})$ & -0.871 & -0.208 & -0.328 \\
\hline & Body mass (kg) & -0.83 & 0.09 & -0.661 \\
\hline & BMI $\left(\mathrm{kg} / \mathrm{m}^{2}\right)$ & -0.327 & 0.098 & -0.828 \\
\hline \multirow{4}{*}{$\mathrm{G} / \mathrm{O}$} & Age (years) & 0.738 & -0.316 & 0.184 \\
\hline & Body height $(\mathrm{cm})$ & 0.105 & -0.949 & 0.038 \\
\hline & Body mass (kg) & 0.949 & -0.105 & -0.086 \\
\hline & BMI $\left(\mathrm{kg} / \mathrm{m}^{2}\right)$ & 0.949 & -0.105 & -0.124 \\
\hline \multirow{4}{*}{$\mathrm{B} / \mathrm{N}$} & Age (years) & 0.04 & 0.22 & 0.11 \\
\hline & Body height $(\mathrm{cm})$ & 0.318 & 0.225 & 0.588 \\
\hline & Body mass (kg) & 0.049 & 0.038 & 0.365 \\
\hline & BMI $\left(\mathrm{kg} / \mathrm{m}^{2}\right)$ & -0.1 & -0.118 & 0.204 \\
\hline \multirow{4}{*}{$\mathrm{B} / \mathrm{O}$} & Age (years) & -0.344 & -0.516 & -0.101 \\
\hline & Body height $(\mathrm{cm})$ & -0.918 & -0.803 & -0.414 \\
\hline & Body mass (kg) & -0.894 & -0.783 & -0.269 \\
\hline & $\mathrm{BMI}\left(\mathrm{kg} / \mathrm{m}^{2}\right)$ & -0.894 & -0.783 & -0.164 \\
\hline
\end{tabular}

$\mathrm{G} / \mathrm{N}$ - girls of normal weight, G/O - girls considered overweight or obese, B/N - boys of normal weight,

$\mathrm{B} / \mathrm{O}$ - boys considered overweight or obese, BMI - body mass index

namic strength test. For boys with normal body weight, the results of the balance test and arm movement speed test changed significantly. The range of the changes in particular fitness tests are presented in Figure 2, whereas Table 3 provides their statistical significance.

As presented in Table 4, in the group of girls who had normal body mass and the group of boys who were overweight, there was a negative correlation between the differences obtained in the balance test and the anthropometric parameters. A positive correlation was observed in girls with normal body mass. No correlation was revealed between the groups and changes in the Eurofit tests in the hand speed, flexibility, or functional strength tests.

\section{Discussion}

In the last decade the level of fitness has been changing dynamically. The results of fitness tests show a trend of decreasing strength and physical performance in early childhood. All tests requiring the generation of static or dynamic muscle strength provided considerably lower results in our own research in comparison with referential values from 16 years ago. Lower test results in the number of pull-ups and sit-ups, coupled with a decrease in the length of jumps, show lessened performance ability, and may also be an indication of lower skeletal muscle strength in children.

Boys of normal body weight performed better than those with excess body weight and obesity in tests requiring precision and movement coordination. This was confirmed by better balance and speed of arm movement test results, as well as by referential values mapped on the percentile chart by Stupnicki et al. [16]. Excess body fat made pull-ups difficult among boys with FatP values above $20 \%$ of body weight. They achieved a lower score on this test when compared with normal body weight boys. This difference was less no- ticeable in the case of girls. High FatP also affected the test results related to coordination and balance. For both overweight girls and boys, test results were lower than those of their peers with normal body weight. The results of our research also showed lower results in the test for flexibility in all study groups. Apparently, time devoted to stretching muscles (especially muscles from the sciatic-tibial group and back muscles) was not sufficient to influence differences in the flexibility test. Our previous study examined the fitness of 93 girls in early childhood from a large city. Higher results in the balance test were achieved. Girls of normal body weight had results of $52.7 \pm 8.0$, whereas the outcomes among overweight girls was $52.1 \pm 8.3$ [17]. In studies in which boys were examined, the results were also higher than average: boys of normal weight had results of $52.8 \pm 10.1$, whereas in overweight boys the outcome was $52.1 \pm 9.7$ [18]. The higher results of children from more urbanized areas may have been related to their participation in extracurricular activities more often than in the case of groups from rural areas. The poor results of the fitness test match the poor results of the 'step test' in a study conducted by Ratajczak et al. [19] among children aged 8-9 years. In this group, $36.4 \%$ of subjects performed poorly or were unable to finish the test owing to high blood pressure (4.5\%).

Improved results were observed in most aspects of the Eurofit testing in children who participated in 10 weeks of karate training. Balance test results improved significantly, especially for girls and boys of normal body weight: 0.015 for girls, 0.028 for boys. An assumption was made that exercises requiring rotations and whole body movements in the chosen karate stances, Zenkutsu Dachi and Sanchin Dachi, improved the results of the balance test in the researched group. The effectiveness of martial arts training in improving balance was previously confirmed by other researchers as well. Dahmen-Zimmer and Jansen [20] examined 37 pa- 
tients suffering from Parkinson's disease who had taken karate lessons, as well as dance lessons. The group of participants who took karate training included 16 people who trained once a week over the course of 3 weeks.

The present research revealed an improvement in the dynamic strength test, which indicated longer distance jumps. Statistical significance was observed in the groups of girls with normal and excess body weight, as well as in the group of overweight boys. The improved results in dynamic strength may be related to the increased number of lower limb exercises, such as hare jumps, jump-overs in crouching position, dynamic swings of lower limbs, and kick techniques, including Mae Geri, Hiza Gamen-Geri, or Kin Geri. A significant increase in torso muscular strength was also observed in girls of normal body weight; this test demonstrated a significant value of 0.007 . Boguszewski and Socha examined 88 children of pre-school age and reported an increase in the abdominal muscle strength of children who had participated in a series of karate lessons [21].

A strong correlation (0.949) between overweight in girls and improved results of balance tests was observed. Girls with the highest body weight improved the most on the balance test. This may indicate lower threshold values needed to make progress in the chosen test. In the case of boys, anthropometric values such as height, body mass, and BMI demonstrated an opposite correlation $(0.918,-0.894$, and 0.894 , respectively) with progress in balance value. Shorter boys with lower FatP achieved greater improvement in the conducted test. Similar results were noted in girls of normal body weight. Other research measured the effects of 6 months of capoeira training, a Brazilian martial art which includes elements of dance and acrobatics. Overall, 67 children aged 16 years were examined, with no previously established correlation between anthropometric values and the Eurofit balance test. Nevertheless, a positive correlation between the subjects' body weight and tests utilizing lower limbs was confirmed. This can be explained by the considerable use of the lower limbs in capoeira training, a significant aspect of which is maintaining control of one's centre of gravity while changing stances. This training also involves exercises which greatly focus on lower limb muscles. The results of this research also highlighted the significant influence of being overweight on performance in endurance tests. It also confirms the relationship between the level of physical performance and BMI [22, 23].

Greater improvement in jumping was achieved by girls with lower body weight, which is indicated by a negative correlation amounting to 0.661 . In turn, in the case of boys, the determining factor for improvement in the jump test was body height (0.588).

The prepared series of karate training showed an improvement in the fitness of the examined group. Lengthening of the training program should be considered in order to measure its long-term effects. Karate training may possibly be a positive alternative to the sedentary lifestyle of children in terms of how they spend their leisure time. It is a proactive and comprehensive form of engaging body into movement and allows to introduce numerous changes to training. This work-out may have a positive effect on health in childhood and in adulthood as well.

A physiotherapeutic cycle which includes elements of karate training has led to improved results in children of both normal and excessive body weight. It may be an indication of the positive influence of this type of activity on early childhood development.
The aforementioned karate training does not require specialized equipment and can be implemented on a widespread level as part of physical education classes in schools.

\section{Conclusions}

1. The 10-week karate training program positively influenced the physical fitness of the examined group of children. Particular emphasis was placed upon balance, hand speed, and dynamic strength.

2. In both overweight boys and girls, a statistically significant improvement was observed.

3. In groups with normal body mass, more statistically significant differences in the Eurofit results were observed when compared with the group considered overweight or obese.

\section{Acknowledgements}

We would like to thank the Nicolaus Copernicus Elementary School in Lewin Brzeski for help in organizing screening and making the gymnasium available for the trainings. We also thank the IFK Karate Club in Lewin Brzeski for help in designing a training plan for school-age children.

\section{Disclosure statement}

No author has any financial interest or received any financial benefit from this research.

\section{Conflict of interest}

The authors state no conflict of interest.

\section{References}

1. Chwałczyńska A, Rutkowski T, Jędrzejewski G, Wójtowicz D, Sobiech KA. The comparison of the body composition of children at the early school age from urban and rural area in southwestern Poland. BioMed Res Int. 2018;9694615; doi: 10.1155/2018/9694615.

2. Donnelly JE, Hillman $\mathrm{CH}$, Castelli D, Etnier JL, Lee S, Tomporowski $\mathrm{P}$, et al. Physical activity, fitness, cognitive function, and academic achievement in children: a systematic review. Med Sci Sports Exerc. 2016;48(6):11971222; doi: 10.1249/MSS.0000000000000901.

3. Janssen I, Leblanc AG. Systematic review of the health benefits of physical activity and fitness in school-aged children and youth. Int J Behav Nutr Phys Act. 2010; 7:40; doi: 10.1186/1479-5868-7-40.

4. Ortega FB, Ruiz JR, Castillo MJ, Sjöström M. Physical fitness in childhood and adolescence: a powerful marker of health. Int J Obes. 2008;32(1):1-11; doi: 10.1038/ sj.ijo.0803774.

5. World Health Organization. Global recommendations on physical activity for health. WHO; 2010. Available from: https://www. who.int/dietphysicalactivity/factsheet_recommendations/en/.

6. Regulation of the Minister of National Education of 28 March 2017 on the outline timetables in public schools [in Polish]. Journal of Laws 2017, item 703.

7. Ćwirlej A, Walicka-Cupryś K, Gregorowicz-Cieślik H. Motor activity of children aged 10 in free time [in Polish]. Przegl Med Uniw Rzesz. 2005;3:262-266.

8. Łuszczki E, Dereń K, Baran J, Weres A, Mazur A. The secular trend of overweight and obesity in preschool children from Rzeszow region. Pediatr Endocrinol. 2015;14.4.53:29-34; doi: 10.18544/EP-01.14.04.1628.

9. Felińczak A, Hama F. The occurrence of the phenomenon of overweight and obesity among children and 
adolescents in Wroclaw [in Polish]. Piel Zdr Publ. 2011; 1(1):11-18.

10. Chwałczyńska A, Jędrzejewski G, Socha M, Jonak W, Sobiech KA. Physical fitness of secondary school adolescents in relation to the body weight and the body composition: classification according to WHO (part I). J Sports Med Phys Fitness. 2017;57(3):244-251; doi: 10.23736/S0022-4707.16.05664-4.

11. Trzcińska D, Olszewska E, Tabor P. Physical fitness and body posture of 7-years-old children with extreme somatic parameters [in Polish]. Pediatr Endocrinol Diabetes Metab. 2009;15(3):188-195.

12. Chaabène $H$, Hachana $Y$, Franchini $E$, Mkaouer $B$, Chamari K. Physical and physiological profile of elite karate athletes. Sports Med. 2012;42(10):829-843; doi: 10.2165/ 11633050-000000000-00000.

13. Chang YC, Yeh TM, Pai FY, Huang TP. Sport activity for health!! The effects of karate participants' involvement, perceived value, and leisure benefits on recommendation intention. Int $\mathrm{J}$ Environ Res Public Health. 2018;15(5); doi: 10.3390/ijerph15050953.

14. Kułaga Z, Litwin M, Tkaczyk M, Palczewska I, Zajączkowska M, Zwolińska D, et al. Polish 2010 growth references for school-aged children and adolescents. Eur J Pediatr. 2011;170(5):599-609; doi: 10.1007/s00431010-1329-x.

15. Różdżyńska-Świątkowska A, Kułaga Z, Grajda A, Gurzkowska B, Góźdź M, Wojtyło M, et al. Height, weight and body mass index references for growth and nutritional status assessment in children and adolescents 3-18 year of age [in Polish]. Stand Med Ped. 2013;1: 11-21.

16. Stupnicki R, Przewęda R, Milde K. Percentile reference curves for physical fitness measured by Eurofit tests in Polish youths [in Polish]. Warszawa: AWF; 2003.

17. Rutkowski T, Jędrzejewski G, Angelus K, Sobiech K, Chwałczyńska A. Physical fitness and body composition of girls in early school age [in Polish]. In: Bogusz M, Wojcieszak M, Rachwał P (eds.), Broadening horizons [in Polish], vol. 6. Słupsk: Mateusz Weiland Network Solutions; 2017; 110-119.

18. Jędrzejewski G, Rutkowski T, Angelus K, Sobiech K, Chwałczyńska A. Physical fitness of boys in early school age in the prevention of overweight and obesity [in Polish]. In: Bogusz M, Wojcieszak M, Rachwał P (eds.), Broadening horizons [in Polish], vol. 6. Słupsk: Mateusz Weiland Network Solutions; 2017; 99-109.

19. Ratajczak J, Raducha D, Horodnicka-Józwa A, Kilian A, Demiaszkiewicz M, Bartoszewicz K, et al. Assessment of physical fitness of 8 and 9-year-old children from Szczecin, Poland, involved in the obesity prevention program - pilot study. Pediatr Endocrinol Diabetes Metab. 2018; 24(2):65-71; doi: 10.18544/PEDM-24.02.0104.

20. Dahmen-Zimmer K, Jansen P. Karate and dance training to improve balance and stabilize mood in patients with Parkinson's disease: a feasibility study. Front Med. 2017;4:237; doi: 10.3389/fmed.2017.00237.

21. Boguszewski D, Socha M. Influence of karate exercises on motor development in pre-school children. J Combat Sports Martial Arts. 2011;2(2):103-107; doi: 10.5604/ 20815735.1047142.

22. Witte K, Emmermacher P, Pliske G. Improvement of balance and general physical fitness in older adults by karate: a randomized controlled trial [in German]. Complement Med Res. 2017;24(6):390-393; doi: 10.1159/ 000479151.
23. Ridan T, Kozaczko M, Ogrodzka K, Jankowicz-Szymańska A, Stożek J. The impact of a six-month capoeira training on the development of motor skills in junior high school students [in Polish]. In: Barnaś E (ed.), Man in health and illness [in Polish]. Tarnów: PWSZ; 2016; 610-622. 